\title{
ARQUIVOS
}

\section{O DEPARTAMENTO DO ARQUIVO DO ESTADO DE SÃO PAULO (1).}

O Departamento do Arquivo do Estado de São Paulo, ora subordinado à Secretaria da Educação, é a repartição pública mais antiga de São Paulo e, talvez, uma das mais bem organizadas, se bem que ainda desconhecida de muitos eruditos. Remonta ao ano de 1721 , mais precisamente a 16 de setembro de 1721, data em que foram inventariados livros e papéis existentes na antiga Secretaria do Govêrno, a fim de instrumentar os primeiros atos do Governador e Capitão General, D. Rodrigo César de Menezes, o primeiro que, efetivamente residiu nesta Capital.

Quanto à organização se, por um lado não conta com um processo arquival, semelhante a modelares instituições que sabemos existir em outros centros culturais, por outro não é e não pode ser considerado um cemitério de documentos, um amontoado de papéis atirados a um canto.

Procurar-se-á neste nosso depoimento, alicerçado em compıovantes transportados, sob custódia, da própria Repartição, informar que o Departamento do Arquivo do Estado está em condições de oferecer um clima de pesquisa aos estudiosos, desde que os mesmos não sejam muito exigentes e saibam compreender a invulgar dedicação de seus funcionários, que preservam, restauram, selecionam os documentos e, ainda vem organizando fichas de quase tôda a documentação, fichas que instrumentam um précis ou uma súmula de cada documento, com indicação numérica da pasta correspondente. Ainda, publicaram centenas de volumes reunidos em séries intituladas: Inventários e Testamentos, Documentos Interessantes, Sesmarias, Boletins, Documentos avulsos - de distribuição gratuita às instituições culturais do país e do estrangeiro, como também aos interessados. Mais ainda. Mantém o ritmo de leitura paleográfica de outra centena de volumes que, copiados e revisionados, aguardam "verba" para efetiva divulgação. Aí está um dos problemas cruciantes do Departamento do Arquivo, que,

(1). - Conferência pronunclada no Salão Nobre da Faculdade de Filosofia, Ciências e Letras da Universidade de São Paulo, na reunião mensal de 19 de malo de 1961, da Socledade de Estudos Históricos. 
sábemos, não é específico, mas constante preocupação de outras entidades culturais, interdependentes de efetivo interêsse de homens públicos responsáveis pelas mesmas. Sabendo tudo isto pode-se culpar o Departamento do Arquivo pelas deficiências que ainda não foram superadas?

\section{O EDIFICIO.}

Tendo presente que a própria palavra: arquivo - archeion, significa: edifício público, casa de Câmara - julgamos interessante começar focalizando o problema da sede.

O Departamento do Arquivo do Estado está instalado em prédio alugado, sito à rua Dona Antônia de Queiroz, n. 183, apenas a uma quadra e meia desta Faculdade. Prédio que, apesar de oferecer condições de trabalho, não é a solução desejada requerida. Esta sòmente se efetivará com a construção e instalação no edifício próprio, cuja planta foi aprovada pelo Departamento de Obras Públicas da Secretaria da Viação em 1940, e cuja tramitação de processo deve estar atolada na engrenagem administrativa. Não conhecemos detalhes do projeto, mas o aspecto da fachada nos leva a admitir certa semelhança com o edificio da nossa Biblioteca Municipal. Quanto ao local, informa o mesmo projeto, foi designado um próprio do Estado, sito entre as Ruas Guaianazes e Alameda Nothmann, onde hoje está instalada a Polícia Feminina. Sòmente com a efetiva construção do edifício, acreditamos que seriam superadas as vicissitudes funcionais provocadas, também, pelo sobressalto das mudanças e conseqüente noticiário capcioso de alguns periódicos desta capital.

Como se pode constatar pelo Pequeno Histónico e Prontuário do Departamento do Arquivo do Estado (2), que temos em mãos, essas vicissitudes remontam às origens do próprio Arquivo - quando numa das dependências do Palácio do Capitão General Rodrigues César de Menezes, seu primeiro secretário, Gervásio Leite Rebelo em 1721, reuniu livros e papéis do antigo govêrno e cuja continuidade esforçou-se para assegurar. E o conseguiu até 1748. Suprimida a capitania de São Paulo, muitos dos papéis arquivados desapareceram ou dispersaramse, remetidos ao governador da Praça de Santos ou então ao vice-rei, no Rio de Janeiro. Com o restabelecimento em 1765 (carta Régia de 6-1-1765) - o novo Capitão General Luís An-

(2). - Sâo Paulo, 1953, págs. 65, 68, 75, 78 e 88). 
tónio de Souza Botelho Mourão, ao instalar a sede da capitania no antigo convento dos jesuítas (pátio do Colégio) determinou que fôssem recolhidos papéis e documentos esparsos, reunindo-os no porão do edifício governamental. Nesse local iristalou-se o Arquivo de 22-VII-1765 a 13-VIII-1906, data em que foi transportado para o andar térreo dos fundos da Igreja dos Remédios, e da Biblioteca do Estado, com entrada pelo n. so da rua Onze de Agôsto. Algum tempo depois, nos últimos meses de 1912, considerando tanto a inadaptabilidade do edifício, como o crescimento do acervo, transferiu-se a sede do Arquivo para um prédio sito à rua Visconde do Rio Branco, esquina com a rua Timbiras n. 31 (alterado para 33 e mais tarde, 237) on-: de teve oportunidade de funcionar de 1912 a 1949. Nesse ano, dada a desapropriação do prédio pela Prefeitura para alargamento da rua, o Arquivo foi obrigado a desocupá-lo repentinamente, indo para o Largo General Osório n. 86 - até então ccupado pela Secretaria da Segurança Pública - e parte para a Borges de Figueiredo, 1216, num armazém da CAGESP. Depois de reinstalado e reorganizado, o Arquivo voltou a ser franqueado aos estudiosos e interessados, como também tiveram seqüência os planos de leitura paleográfica e conseqüente publicação de documentos vinculados ao passado histórico de São Paulo. Todavia, medidas burocráticas exigiram uma nova mudança, que se positivou em março de 1953, quando foi encontrado, alugado, adaptado e instalado o Arquivo no prédio que hoje ocupa, à rua Dona Antônia de Queiroz, 183. Trata-se de uma propriedade particular, a antiga Fábrica Tapetes Santa Helena, que, apesar de não ser ideal, conta com características positivas. Corresponde a uma área útil superior a 3.000 metros quadrados, ocupada por sólida construção, podendo receber pêso superior a 600 quilos por metro quadrado, nos salões destirados às prateleiras de aço padronizadas. Possui ainda prédio de dois andares, em anexo, para depósitos, católogos de documentos e oficinas especializadas para restauração e encadernação. Tem ainda laboratório e demais dependências de microfilmagem. Nas diferentes secções há estantes de aço desmontáveis em número de 145 , medindo cada uma $19,20 \mathrm{cms}$. Nelas são colocadas as latas de alumínio, de tamanho padronizado, hermèticamente fechadas, com etiqueta móvel para identificação. Foram adquiridas em 1953, sendo que sòmente na seção histórica há 8.000 delas.

Outros detalhes poderiam ser lembrados, mas realmente o problema das mudanças do Arquivo - que na realidade po- 
dem ser reduzidas a duas: da rua Visconde do Rio Branco para o Largo General Osório e rua Borges de Figueiredo e dêstes locais para a rua Dona Antônio de Queiroz - interessa a dois grupos, em conflito apaixonado. Um dêles alega que muitos documentos preciosos foram perdidos. $O$ outro, dos funcionários do Arquivo, proclama que nada se perdeu, que os pacotes foram controlados e transportados sem dificuldades insuperáveis. Argumentam com publicações baseadas em documentos lidos e copiados antes das mudanças e que depois, ainda lá se encontram, intactos, podendo ser consultados pelos interessados.

Quanto a nós, achamos que os resultados de uma mudança, mesmo com um acervo menor e menos precioso, são incontroláveis, caso o material não haja sido rigorosamente catalogado. T'odavia, afigura-se nos digna de ponderação a réplica dos funcionários, acima mencionada. Concluindo, devemos reconhecer que o problema do edifício do Departamento do Arquivo do Estado foi atenuado, mas sòmente será solucionado com a construção do prédio próprio, em local a ser reconsiderado.

\section{NOTAS HISTÓRICAS.}

A semente do atual Departamento do Arquivo foi lançada aos 16 de setembro de 1721, como já dissemos, pelo então secretário do govêrno da capitania, Gervásio Leite Rebelo.

Todavia, a existência oficial se efetivou cêrca de um século mais tarde. A 8 de março de 1842 , através da lei n. 20, promulgada pelo barão de Monte Alegre (José da Costa Carvalho), foi criado o Arquivo Público e determinado o quadro de funcionários. Medidas efetivas foram objeto de outras mensagens governamentais. Perdurou tal situação até a época republicana, quando o vice-presidente do Estado, no exercício da presidência, assinou o decreto n. 30 , de 10 de março de 1892, criando a Repartição de Estatística e anexando a ela o Arquivo Público, como repartição subordinada à Secretaria do Interior. Com o decreto n. 497, de 3 de março de 1931, que transformou a Secretaria do Interior na Secretaria da Educação e Saúde Pública, houve o desmembramento da seção de Estatística e Arquivo Público, para a Secretaria da Justiça. Durou pouco essa vinculação, porque a 27 de outubro do mesmo ano, o Decreto n. 5.243 fêz retornar a citada repartição para a Secretaria da Educação, onde ainda hoje se encontra. Posteriormente, pelo decreto n. 9.285, de 1 de julho de 1938, a repartição passou a ser identificada pelo seu nome atual - Departamento do Arquivo 
do Estado, e reorganizada com as três secções existentes: I. secção administrativa; II. - secção Histórica; III. - secção de Expediente e Contabilidade.

Sabe-se que em 1952, encaminhou-se ao Sr. Governador do Estado, Prof. Lucas Nogueira Garcez, através da Secretaria da Educação, um ante-projeto de reforma, pelo qual não sc̀mente se ampliaria os quadros de funcionários, como também se aventada a sua transferência para a Secretaria do Govêrno, isso tudo dentro da linha do Plano Quadrienal, previsto pelo govêrno da época. No entanto, até a presente data, o Departamento do Arquivo do Estado continua subordinado à Secretaria da Educação e os problemas de reorganização, como é óbvio, continuarão aguardando providências necessárias à sua. efetiva solução.

\section{A ATUAL ESTRUTURA.}

Como dissemos acima, de acôrdo com a regulamentação de 1. -VII-1938, o Departamento do Arquivo do Estado está estzuturado em três seções - Administrativa, Histórica, Expediente e Contabilidade - com objetivos definidos e equipadas. de maneira a satisfazer as finalidades precípuas da própria repartição que, além do campo cultural, engloba funções burocráticas, justificando estar assim vinculada à Secretaria da Educação, pois conserva-lhe o "arquivo vivo" até os últimos. cinco anos, guardando todos os papéis da Secretaria da Educação até o ano dúe 1957.

Consta que deveria receber idêntica papelada das demais Secretarias governamentais. Não o faz por falta de instalações e de pessoal.

\section{1. - A Secção Aldministrativa.}

À secção Administrativa, além do arquivo acima mencionado (que se cifra em toneladas de papéis empacotados contendo duplicatas da freqüência de professôres, petições, requerimentos de funcionários, fôlhas de pagamento, livros de ponto, etc.) compete guardar:

1. - Talões canhotos de Registro Civil e Imobiliário. Essa atribuição é uma conseqüência dos decretos federais $n$. 18.542, de 24-XII-1928, e n. 4.857, de 9-XI-1939. Ao apresentar o problema dêsses conhotos, temos presente as ponderações do sr. diretor do Arquivo Público Mineiro (Dr. João Gomes Tei- 
xeira) em 1958, sôbre os transtornos que os mesmos acarretam à sua Repartição. Mais ainda. Sabemos que desde 1954 em ofícios e relatórios anuais, o diretor do Arquivo, dr. José Soares de Souza, vem sugerindo modificações dos decretos, no sentido de serem os talões canhotos arquivados nas Prefeituras locais. Modificações essas que, consideradas e executadas por quem de direito, viriam trazer um benefício imenso aos Arquivos Públicos de todos os Estados brasileiros.

Quanto a instrumentos de trabalho para os pesquisadores, a secção administrativa pode pôr à sua disposição o arquivo de tôda documentação da capital e do interior referentes à éra republicana, desde a instalação do regime, em 1889 até os nossos dias.

\section{2. - A Secção Histórica.}

A Secção Histórica é, a nosso ver, a mais preciosa pois trata-se duma seç̧ão técnica de estudos e consultas. Compete-lhe vistoriar os documentos antigos do tempo da Colônia e do Império. Êstes, em códices ou volumes manuscritos, são selecionados, desinfetados ou restaurados, conforme o estado em que se encontrem. Depois, fichados e classificados por grupos de assuntos (Autos cíveis - Escravidão - Maços de população - Sesmarias - Igrejas, etc.) em latas de alumínio hermèticamente fechadas. Latas padronizadas, de dimensões uniformes, próprias para serem guardadas em estantes de aço, também padronizadas. Os documentos antes de serem "armazenados", são amarrados e protegidos com capas de papelão, a fim de melhor protegê-los e também evitar desperdício de lugar. Todos êles tem etiqueta móvel com identificação correspondente ao catálogo e às fichas-resumo.

Estas últimas, que estão sendo datilografadas, contém indicação da localidade, datas, limites, remetente e destinatário, informação resumida sôbre o conteúdo, do mesmo documento. Ainda a ficha contém a indicação precisa da estante, maço e número do catálogo. Apesar do tamanho uniforme, por ora não vemos, na secção, um fichário metálico e muito menos uma simbolização pré-estabelecida.

Atribuições. Dentre as atribuições da secção histórica, podem ser consideradas como de ordem geral: Leitura paleográfica e divulgação, efetiva, dos manuscritos arquivados de real interêsse para a história da civilização brasileira. Tarefa que foi e está sendo executada, através dos volumes publicados e a 
publicar. Ainda cabe-lhe manter intercâmbio com instituições culturais e técnicas, oferecendo-lhe informes necessários à concretização de seus objetivos. Exemplificando, podemos citar 0 arrolamento de fontes históricas do prédio da antiga cadeia de Santos, solicitado pelo $4 .^{\circ}$ Distrito da Diretoria do Patrimônio Histórico e Artístico Nacional, interessado no tombamento e eventual restauração daquele monumento histórico. Mais ainda. Atender aos interessados e consulentes, sendo que dentre êstes últimos, alguns são estudants sem os mais elementares corhecimentos para o trabalho que alegam ter necessidade de realizar. Então recebem, com paciência e dedicação inexcedíveis, noções básicas de introdução à pesquisa histórica.

Arquivo privado, secreto. Cumpre notar que nem tôda documentação custodiada na secção histórica, é diretamente franqueada aos consulentes. Classificada e guardada em armários €speciais na própria sala do chefe da secção, acham-se os volurnes que instrumentam as certidões centenárias que, como se sabe são registros de terras de diversas localidades da capital e do interior do Estado, arroladas de 1854 a 1847, em conseqüência do tombamento levado a efeito em 1817. Antes vigoravam as sesmarias (glebas de terras de 6 léguas de frente, com 3 léguas de fundo). Lembramos que os interessados na obtenção de certidões negativas, podem obtê-las mediante um requerimento dirigido ao diretor do Departamento do Arquivo e por êste encaminhado ao funcionário especializado.

Fora esta ressalva, tôda a documentação, tanto inédita como publicada, acha-se à disposição dos interessados, no horário normal da repartição (das 12 às 18 horas, de segunda à sexta-feira e das 9 às 12 horas aos sábados).

Compreendemos e endossamos as reclamações no sentido 'de estender êsse horário aos períodos da manhã e da noite, como ocorre com a Biblioteca Municipal. Adiantamos que a direção do Departamento, igualmente interessada, sòmente não o concretiza devido à falta de funcionários, já angustiosa no horário vigente.

Instrumentos de trabalho. Como instrumentos de trabalho, além dos catálogos impressos, fichários, os próprios documentos originais e secundários, há na secção dois aparelhos sui generis, a estufa e a lâmpada ultra-violeta. A estufa, apelidada de "câmara de gás dos papirófagos", proporciona um excelente processo de desinfecção dos documentos e de outros papéis igualmente infeccionados. Essa desinfecção se faz periòdicamente, também por outros processos: dedetização e BHC. A estufa 
É um armário de aço, de 2,15 metros de comprimento, pesando cêrca de 1.200 quilos, com capacidade para mais de 20 volumes de cada vez. Internamente está dividida em três prateleiras perfuradas (como os fornos de certos restaurantes). Os documentos, sendo volumes, são colocados abertos, juntamente com pastilhas de formoforme mergulhadas numa vazilha, comumente de pirex, com água. A temperatura é elevada a 65 graus centígrados, durante 5 horas. Pela volatização das pastiihas processa-se a desinfecção reforçada ainda mais pela ação do calor. Essa estufa, adquirida em 1945 e em atividade continua desde 1955 serve, não sòmente ao Departamento do Arquivo, como a outras repartições oficiais e ainda aos particulares (sem nenhum ônus, desde que assim o requeiram à direção do Departamento). E' curioso lembrar que a desinfecção não se limita a documentos manuscritos e impressos, pois recentemente tivemos oportunịdade de ver molduras de madeira, de galeria dos presidentes do Estado (do Palácio do Govêrno), submetidas ao processo acima descrito.

Lâmpada ultra-violeta. A aquisição de um aparelho de luz ultra-violeta, quando das instalações da rua Visconde do Rio Branco, faculta a funcionários especializados da secção histórica e àquêles familiarizados com leitura paleográfica a leitura e interpretação de textos antigos que, danificados pela humidade e outros fatôres, apresentam dificuldades a leitura a ôlho nu. Trata-se de uma lâmpada, adaptada, cujo uso requer cuidado, pois diretamente ataca a vista. Considerando que a tinta então usada era fabricada com sais ferrosos, essa lâmpada aplicada numa câmara escura, provoca um fosforescência que eqüivale a revitalização da escrita. Outros testes, curiosos, podem ser feitos, para justificar uma prova de autenticidade. Exemplificando, uma jóia, uma pérola, sendo autêntica permanece natural, caso seja falsa, êi-la prêta, como carvão. Mesmo os dentes naturais e artificiais, são provados e comprovadós pela lâmpada ultra-violeta que sòmente respeita o que é autêntico. Lamentàvelmente escapa-lhe o elemento humano e ela não pode separar os pesquisadores autênticos, dos rotulados...

Preciosidade da seç̧ão. O documento mais antigo do Departamento remonta ao quinhentismo. Precisamente ao ano de 1578, que é a data do inventário de Damião Simões (natural de... e falecido a... em São Paulo do Campo).

Este inventário não foi restaurado, como se pode ver, mas foi obejto de leitura paleográfica e publicado, na íntegra no 
vol. I de Inventários e Testamentos (3), que temos sob as mãos'. Igualmente remonta ao quinhentismo, o primeiro documento, em ordem cronológica, restaurado, depois de copiado e publicado. F' o testamento de Salvador de Chaves e sua mulher, Polonia Domingues, ambos naturais de..., falecidos em...

O documento, datado de 1599 , está, como se pode comprovar, restaurado e publicado na íntegra neste vol. 30, de Inventários e Testamentos (4).

Ainda temos em mãos um precioso livro de correspondência do capitão-mor, Dom Luís Antônio de Souza Botelho Mourão, o Morgado de Mateus, livro que foi restaurado e graças a processos técnicos, conservou a própria capa de couro. Antes da restauração, como é usual, foi objeto de leitura paleográfica, copiado e divulgado na íntegra, no vol. n. 65, de Documentos Interessantes (5), que também temos aqui ao lado.

Concluindo, podemos afirmar que a existência dêstes três documentos acima citados, copiados e publicados antes das problemáticas mudanças do Departamento do Arquivo, e ainda hoje conservados tal qual estavam naquela ocasião, constitui ponderável argumento a favor da tese dos funcionários da própria repartição, de que nada de precioso foi perdido ou notada foi a sua perda, com os processos de mudança do acervo do Departamento do Arquivo.

\section{3. - Seç̧ão de expediente e contabilidade.}

Esta seç̧ão, além das funções administrativas de rotina, mantém intercâmbio cultural, tanto direta, como indiretamente, através de sugestões recebidas de visitantes credenciados - dentre os quais destacamos em 1959 as de John Harrisson, do National Archives de Washington - com quem o Arquivo permuta suas publicações.

Vinculam-se-lhe três outros serviços: biblioteca, oficina de restauração e encadernação, laboratório de microfilmagem .

Biblioteca. $O$ acervo é formado por publicações impressas, adquiridas por doação ou compra, de acôrdo com os próprios objetivos culturais. Esse acervo está sendo objeto de classificação decimal, pela atual funcionária, que é técnica especializada, diplomada pela Escola de Biblioteconomia de São Paulo. Preocupa-lhe e muito a atualização ou elaboração de um catá-

(3). - São Paulo, ano 1920, pág. 3.

(4). - São Paulo, ano 1939, pág. 7.

(5). - Sāo Paulo, 1940, pág. 9. 
logo da Biblioteca, com o seu indispensável fichário, pois o existente, publicado em 1941, não satisfaz às exigências mínimas dos consulentes. A Biblioteca, especializada em História de S. Paulo e do Brasil, conta com alguns exemplares raros e também com uma preciosa coleção de Alvarás (Cartas Régias), Leis e Decretos, Atas de Assembléias, etc. que chegam a remontar aos tempos coloniais. Ainda merece destaque a seç̧ão de periódicos editados na capital e no interior, e alguns provenientes de outros Estados. Algumas dessas coleções são mais completas que aquelas existentes nos arquivos das próprias emprêsas jornalísticas que vem recorrendo ao Arquivo, a fim de complementar com cópias fac-similares, as suas próprias coleções. Ainda um outro setor da Biblioteca merece ser divulgado. Trata-se da receptividade da bibliotecária - que também cursou a secção de Geografia e História da Faculdade de Filosofia, Ciências e Letras da Universidade de S. Paulo - ao apêlo do Prof. E. Simões de Faula, no sentido de ser providenciado o arrolamento das fontes primárias das localidades do interior e regiōes circunvizinhas (6).

Esse serviço começou com uma carta-circular enviada a tôdas as Prefeituras do interior do Estado e o Arquivo vem catalogando as respostas que eventualmente poderão representar um belo instrumento de trabalho aos estudiosos e aos estudantes dos cursos de História Local ou Regional que forem ministrados nas secções especializadas do ensino superior de nosso Estado.

Oficina de restauração e éncadernação. No andar térreo está instalada uma modesta, mas impressionante oficina de restauração dos documentos danificados pela ação do tempo, insetos e acidentes outros. Depois de convenientemente recuperados, êsses documentos, na maioria dos casos, são encadernados na rnesma oficina, pelo mesmo e único funcionário - um auto-didata autêntico que, fazendo lembrar aquelas corporações medievais, adquiriu os necessários conhecimentos técnicos com seu próprio pai, hoje funcionário aposentado. Não sabemos quantos documentos foram por ambos preservados, recuperados, como também o número de volumes encadernados nessa modesta e fecunda oficina.

Laboratório de microfilmagem. Como não poderia deixar de ser, o Departamento do Arquivo do Estado conta com uma sala destinada ao laboratório de microfilmagem, como também

(6). - Revista de História, São Paulo, 1959, n.० 39, pág. 209, nota de rodapé. 
com aparelho ampliador para leitura paleográfica e estudo detalhado.

Aquêle serviço, apesar de não contar com certos cuidados como: ar acondicionado, acondicionamento de microfilmes em recipientes adeqüados e com material especial que lhe garantam resultados absolutos num longo prazo - 180 a 200 anos -- mesmo assim êsse laboratório vem prestando relevantes serviços ao Departamento e aos consulentes.

Cópias facsimilares. Como o aparelho de microfilmagem não está em funcionamento, por ora os documentos, além de serem emprestados aos interessados, para consulta interna, são levados para fora, quando se faz necessária a sua reprodução facsimilar ou microfilmagem, o que ocorre com tôdas as garantias, mediante a aquiescência do Diretor do Arquivo, que despacha o requerimento do interessado e designa um funcionário para levá-lo ao local mencionado, comumente ao serviço de Documentação da Reitoria da Universidade de São Paulo (7), ou à laboratórios particulares.

\section{RELAÇÃO DAS PUBLICAÇÓES DO DEPARTAMENTO DO ARQUIVO.}

Se o teste da fecundidade de uma instituição cultural pode ser verificado pela qualidade e pelo número de suas publicações, o Departamento do Arquivo do Estado merece ocupar lugar de destaque ao lado de suas congêneres. De 1894 a princípios de 1956 publicou cêrca de 154 volumes de textos antigos e ensaios relacionados com a história da civilização paulista. Sabe-se que há outras dezenas de volumes, revisionados, prontos para serem enviados ao prelo, o que não ocorre por falta de verba. Verba cortada em 1955 e que consta estar sendo objeto de liberação. Por outro lado não foi sòmente essa repartição que foi atingida pelo corte de despêsas do govêrno estadual. Dos volumes já publicados, em séries específicas, podemos elaborar um quadro sumário, assim distribuído:

1. - Documentos Interessantes, de 1894 a princípio de 1956: 83 volumes.

2. - Inventários e Testamentos, de 1920 a 1955: 40 volumes.

3. - Sesmarias, de 1921 a 1944: 6 volumes (cumpre notar que não há mais matéria a publicar).

(ग). - Sito à Rua Vieira de Carvalho, 170-5. 
4. - Boletim, de 1942 a 1955: 14 volumes:

5. - Catálogo da Biblioteca, (Departamento do Arquivo do Estado, 1941).

6. - Catálogo da Secção Histórica, 1939.

7. - Pequeno Histórico e Prontuário do Departamento do Arquivo. São Paulo, 1953.

8. - Noções de Paleografia, 1953.

9. - Documentos Avulsos, de 1952 a 1955: 6 volumes.

Como é óbvio, êsses volumes, dos quais alguns já se encontram esgotados, não podem ser adquiridos por compra, mas sim por doação quando solicitada à direção do próprio Arquivo. Informam-nos ainda que tanto os volumes $n .{ }^{\circ} \mathrm{s} 84,85$ e 86 da série Documentos Interessantes, como também o volume 15, da série dos Boletins, já estão no prelo, sendo prevista a sua distribuição em julho vindouro.

\section{QUADRO DE FUNCIONÁRIOS.}

Um último problema e já é tempo de se focalizar o último e, a nosso ver, o mais cruciante de todos os problemas do Departamento do Arquivo do Estado: o quadro de funcionários.

Basta levar em conta que, além de realizar tôdas as funções acima mencionadas, tanto culturais como burocráticas, conta o Departamento do Arquivo do Estado atualmente com um quadro de 41 funcionários, assim distribuídos: o diretor, 3 chefes de secção, sendo um dêles o da Secção Histórica, o paleógrafo do Departamento; 3 assistentes de administração, 1 historiógrafo, 1 artífice, 1 arquivista, 1 bibliotecário, 1 fotógrafo, 13 escriturários e 16 serventes.

Esses funcionários são quase todos auto-didatas, e são êles próprios os primeiros a reclamar uma formação científica e técnica. Fato mais grave dá-se na Secção Histórica, onde os antigos funcionários especializados se vão aposentando, sem haver quem os substitua. Isto acontece porque, dado o pequeno número de funcionários, não há, e nem pode haver, condições para um treinamento sistemático. Ora, um pesquisador, um paleógrafo não se improvisam. São necessárias dedicação e longa prática, além de familiaridade com conhecimentos técnicos específicos.

Sentindo a gravidade do problema, que parece ameaçar a concretização das finalidades precípuas da repartição, os responsáveis pela mesma, além de haver facultado a promçoão de 
um curso prático de Introdução à Paleografia - realizado em 1952 - vem clamando no sentido de racional ampliação do quadro acima apresentado.

Sabe-se que entre os 200 inscritos figuravam a quase totalidade de funcionários categorizados do próprio Arquivo. Ora, $60 \%$ receberam certificado de aprovação. Todavia, até a presente data, apesar de reiteradas solicitações, em caráter oficial, da direção do Arquivo à Secretaria da Educação, nenhum dêles foi aproveitado, nem mesmo o pessoal de casa. $E^{\prime}$ de justiça tornar bem claro que os funcionários efetivos, mormente os da Secção Histórica - com os quais nossa convivên-. cia é maior - sabem que não possuem uma formação técnica especializada, que a classificação do material do Departamento deve ser refeita, com as regras essenciais de seleção e de codificação de "fundos".

Sòmente devidamente equipado, o nosso Arquivo poderá realizar seus objetivos precípuos e situar-se na linha dos $f_{d}$ mosos arquivos internacionais. No entanto, está com "os pés $\epsilon$ as mãos" entravados pela burocracia administrativa que até a presente data não efetivou uma reforma de base, sugerida por técnicos e pela própria repartição em 1952. Todavia, os consulentes assíduos parecem compreender o elevado espírito público, a generosidade sem limites, o invulgar trabalho realizado pelos funcionários daquela secção.

$\mathrm{E}$ neste depoimento em que procuramos manter uma linha de objetividade, justificar-se-ia que destacássemos alguns romes, apenas daqueles que não mais estão vinculados à repartição. Vejamos: o dr. João Alberto Roble, historiógrafo, falecido no efetivo exercício de seu cargo em 1957. Mesmo antes da sua nomeação efetiva, teve oportunidade de prestar relevantes serviços, entre outros, facultando a presença efetiva da Repartição nas comemorações promovida pelo I.H.G.S.P. do cinqüentenário do prêmio Deutsch a Santos Dumont. Mais tarde, sabe-se que elaborou uma cronologia dos fastos de São Paulo, desde sua fundação até 1954, a ser divulgada quando das comemorações do IV centenário da cidade. Mas, dada a t:ansferência de uma "verba", já destinada ao Departamento do Arquivo, para outra instituição, tanto esta, como outras pesquisas, deixaram de ser publicadas.

Dentre os funcionários aposentados, focalizaremos apenas três: o Sr. José Rubi, Da. Maria da Glória Amaral Silveira e $\curvearrowleft$ Dr. Antônio Paulino de Almeida. 
1. - O sr. José Rubi foi admitido aos 9-IX-1929 para exercer as funções de restaurador extranumerário. Efetivado no cargo de encadernador-artífice, do qual se aposentou em 1959, era um auto-didata autêntico. Usava uma técnica que pode merecer críticas, mas que apresenta pontos positivos. Com essa mesma técnica, e mais ainda uma paciência e dedicação sem limites, o "mestre" Rubi, durante aquêles longos. anos salvou milhares de documentos da total destruição. Cumpre informar que seus trabalhos técnicos mereceram admiração, tanto de pesquisadores credenciados, como de técnicos especializados no assunto, da Diretoria do Patrimônio Histórico e Artístico Nacional. E apesar de haver trabalhado sempre sòzinho, parecendo ser o único restaurador no gênero aqui em São Paulo, ao se aposentar (pela compulsória) deixou o lugar para o próprio filho, chamado "Rubi, o moço", que hoje também trabalha sòzinho e é o artífice restaurador e encadernador do Departamento.

2. - A paleógrafa Da. Maria da Glória Amaral Silveira, a querida $\mathrm{Da}$. Glorinha, que se aposentou recentemente (a 128-60), com uma fôlha de serviço inexcedível em dedicação e capacidade técnica. Tanto e tão profundamente chegou a dominar os problemas da Paleografia dos primeiros séculos de nossa História que Paulo Bonfim, em expressivo poema, batizou-a de "anjo tutelar dos consulentes".

Sabemos que além dos trabalhos da própria secção soube ajudar aos consulentes incapazes de sòzinhos vencer certos obstáculos de leitura paleográfica. Da. Glorinha ainda encontrou tempo de tomar suas notas, fazer suas pesquisas em cêrca de 30 anos, cujo resultado estão contidos em dois volumes, trabalho até agora inédito mas que esperamos ver logo publicado.

3. - Finalmente o Dr. Antônio Paulino de Almeida, considerado um dos maiores pesquisadores vivos do Brasil e, inegàvelmente, a maior autoridade sôbre as antigas "Vilas de Marinha" do litoral da então capitania e Província de São. Paulo, posição que levou os alunos da Faculdade de Filosofia, Ciências e Letras de Santos a reverenciá-lo como patrono do seu Centro de Estudos Históricos e que tem o seu nome.

O Dr. Paulino aposentou-se em 1954, forçado pela compulsória, depois de cêrca de $\mathbf{4 0}$ anos de uma impressionante e total dedicação ao Departamento do Arquivo do Estado, cuja seç̧ão histórica êle organizou, cujos documentos selecionou, 
acessorado por uma equipe de funcionários amigos, aposentados uns, outros ainda no efetivo exercício de suas funções. Dir-se-ia que êsses funcionários foram contagiados pelo idealismo sempre presente na vida daquele então jovem promotor público de Cananéia - sua terra natal, - que em 1928 soubera corresponder ao apêlo do então presidente, Dr. Washington Luís, trocando um cargo certo de promotor público, por outro ainda hoje incerto, de arquivista. O vigor intelectual dêsses longos anos, está presente no próprio equipamento da secção que êle organizou como autêntico auto-didata, nos trabalhos divulgados em periódicos de instituições culturais, como também em emprêsas jornalísticas da capital e do interior. Mais ainda, temos em mãos o primeiro de seus livros, Memória Histórica lda Ilha de São Sebastião, publicado na coleção da Revista de História e ainda no volume 47 da referida Revista o $10^{\circ}$ capítulo de sua obra máxima: Canaméia, que também será reunida em um ou dois volumes.

\section{CONCLUSÃO.}

Ao encerrar êste nosso depoimento sôbre a mais antiga repartição pública do Estado, insistimos na invulgar dedicação de seus funcionários que, sem os recursos técnicos necessários e sem formação técnica especializada, - autênticos auto-didatas - vêm fazendo funcionar um valioso instrumento de pesquisa, tão útil aos estudiosos do passado de nosso grande Estádo Bandeirante (9).

MARIA REGINA DA CUNHA RODRIGUES da Faculdade de Filosofia, Ciencias e Letras de Santos e assistente extranumerária de Faleografia, da Faculdade de Filosofia, Ciências e Letras da Universidade de São Paulo.

(8). - Janelro-março de 1961.

(9). - Como decorrência imediata da comunicação acima transcrita, foi constitứda uma comissão de professôres para, conjuntamente com a direção do Departamento do Arquivo do Estado, estudar medidas práticas para revitalizar aquela repartiçáo pública de inexcedivel valor para a pesquisa histórica entre nós. Assim foi elaborado pelo Diretor do Arquivo, Dr. José Soares de Souza, um ante-projeto de lei em que se trata da reforma geral do Arquivo, que achamos de bom alvitre publicar em anexo, enquanto se aguarda um pronunciamento dos membros da referida comissão (Nota da Redaçá). 


\section{ANTE-PROJETO DE LEI}

Reorganiza o Departamento do Arquivo do Estado.

CAP. I - Da nova organização e competência.

Artigo $1^{\circ}{ }^{\circ}-\mathrm{O}$ atual Departamento do Arquivo do Estado, subordinado à Secretaria da Educação, passa a denominar-se "Arquivo Geral do Estado", diretamente subordinado à Secretaria do Govêrno.

Artigo $\left.2 .^{\circ}\right)$ - Compete ao Arquivo Geral do Estado:

I - Guardar, conservar e restaurar documentos, processos, papéis ou livros públicos ou particulares, de qualquer natureza, que possam aproveitar à História do Estado e do Brasil;

II - Centralizar o acervo de todos os arquivos de processos administrativos findos das Diversas Secretarias de Estado e de outros serviços públicos;

III - Ler, interpretar e divulgar os manuscritos arquivados;

IV - Manter intercâmbio cultural e técnico com instituições congêneres, para fins:

a) - de unidade de método de classificação, catalogação, conservação e restauração de documentos;

b) - de informações e de estudos históricos.

$\mathrm{V}$ - Incrementar o interêsse pela pesquisa histórica.

VI - Proceder a estudos de caráter histórico, baseados na documentação de.que é repositório.

VII - Microfotografar ou fotografar os documentos julgados passíveis de perecimento ou de grande raridade, ou ainda outros, para fornecimento aos pesquisadores de história.

Artigo $3 .^{\circ}$ - O Arquivo Geral do Estado compreenderá, além da Diretoria:

a) - 1 Divisão de Administração.

b) - 2 Divisões Técnicas: - Divisão do Arquiva Geral e Divisão do Arquivo Histórico.

c) - Biblioteca.

a) - Laboratório de Microfotografia, Fotografia e Fotocópia.

Artigo $4^{\circ}$ ) - A Divisão de Administração compõe-se de:

a) - Secção de Expediente e Pessoal.

b) - Secção de Protocolo e Almoxarifado.

c) - Zeladoria e Guarda do Patrimônio. 
Artigo $\left.5^{\circ}\right)$ - A Divisão do Arquivo Geral compõe-se de:

a) - Secção do Arquivo Geral.

b) - Secção do Registro Civil e de Imóveis.

Artigo $60^{\circ}$ ) - A Divisão do Arquivo Histórico compõe-se de:
a) - Secção de Paleografia e Pesquisa Histórica.
b) - Secção de Divulgação.
c) - Secção do Arquivo Histórico.
d) - Serviço de Restauração.

Artigo $7 .^{\circ}$ ) - São fixadas as seguintes atribuições aos órgãos do Arquivo Geral do Estado:
a) - Ao Diretor, auxiliado por 2 assistentes de administra- ção e 1 assistente de relações públicas, dirigir, coorde- nar e distribuir, supervisionando-os, todos os serviços administrativos e técnicos.
b) - Ao Sub-Diretor, auxiliar o Diretor em suas tarefas e substituí-lo em seus impedimentos.
c) - A Divisão de Administração executar os serviços ad- ministrativos, inclusive aquêles relativos ao zêlo e guar- da do patrimônio.
d) - Às Divisões Técnicas as discriminadas nos itens I a VI do artigo $2 .^{\circ}$ desta Lei.
e) - À Biblioteca especializada em História de São Paulo, principalmente, e do Brasil, manter devidamente tom- bados, classificados e catalogados os livros, mapas e periódicos.
f) - Ao Laboratório de Microfotografia, Fotografia e Foto- cópia as discriminadas, no item VII do artigo $2 .^{\circ}$ des- ta Lei.

\section{CAP. II - Do Quadro do Pessoal.}

Artigo 8. ${ }^{\circ}$ - Ficam criados no quadro da Secretaria do Govêrno, e lotados no Arquivo Geral do Estado, conforme especificação, vencimento e forma de provimento constantes da Tabela anexa ̀̀ presente Lei, os seguintes cargos

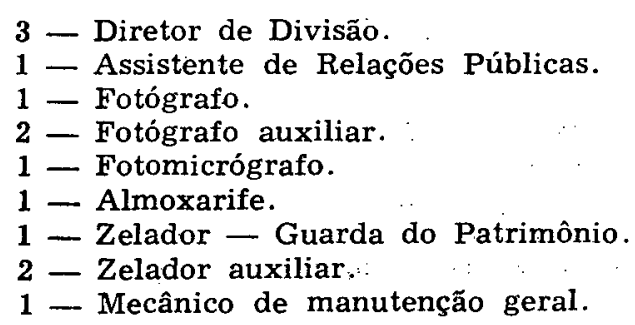




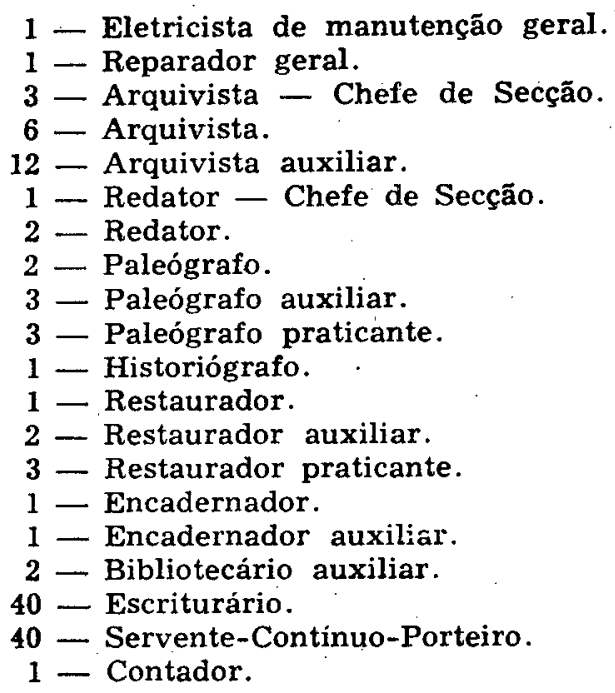

Artigo 9. $)$ - Continuam lotados no Arquivo Geral do Estado, os seguintes cargos:

1 - Diretor, ref. " 75 ".

2 - Chefe de Secção, ref. "50".

1 - Historiógrafo, ref. " 43 ".

1 - Paleógrafo-Chefe de Secção, ref. "50".

2 - Assistente de Administração, ref. "34".

1 - Bibliotecário, ref. " 31 ".

3 - Escriturário, ref. "34".

1 - Escriturário, ref. "31".

2 - Escriturário, ref. "28".

1 - Escriturário, ref. " 26 ".

1 - Escriturário, ref. "22".

4 - Servente-Contínuo-Porteiro, ref. "26".

1 - Servente-Contínuo-Porteiro, ref. "22".

3 - Servente-Contínuo-Porteiro, ref. "15".

1 - Arquivista, ref. " 31 ".

Artigo 10..$^{\circ}$ - Ficam, ainda, criadas, no Arquivo Geral do Estado, as seguintes funções gratificadas:

1 FG. - 5 (encarregado da oficina de Restauração de documentos).

2 FG. - 8 (encarregado da Biblioteca e Laboratório).

Artigo $11 .^{\circ}$ ) - Os cargos ora criados serão preenchidos à medida das necessidades dos serviços do Arquivo Geral do Estado.

Artigo $12 .^{\circ}$ ) - Os titulos dos funcionários que tiverem a sua si-. tuação alterada por esta lei, serão apostilados pelo Secretário do Govêrno. 


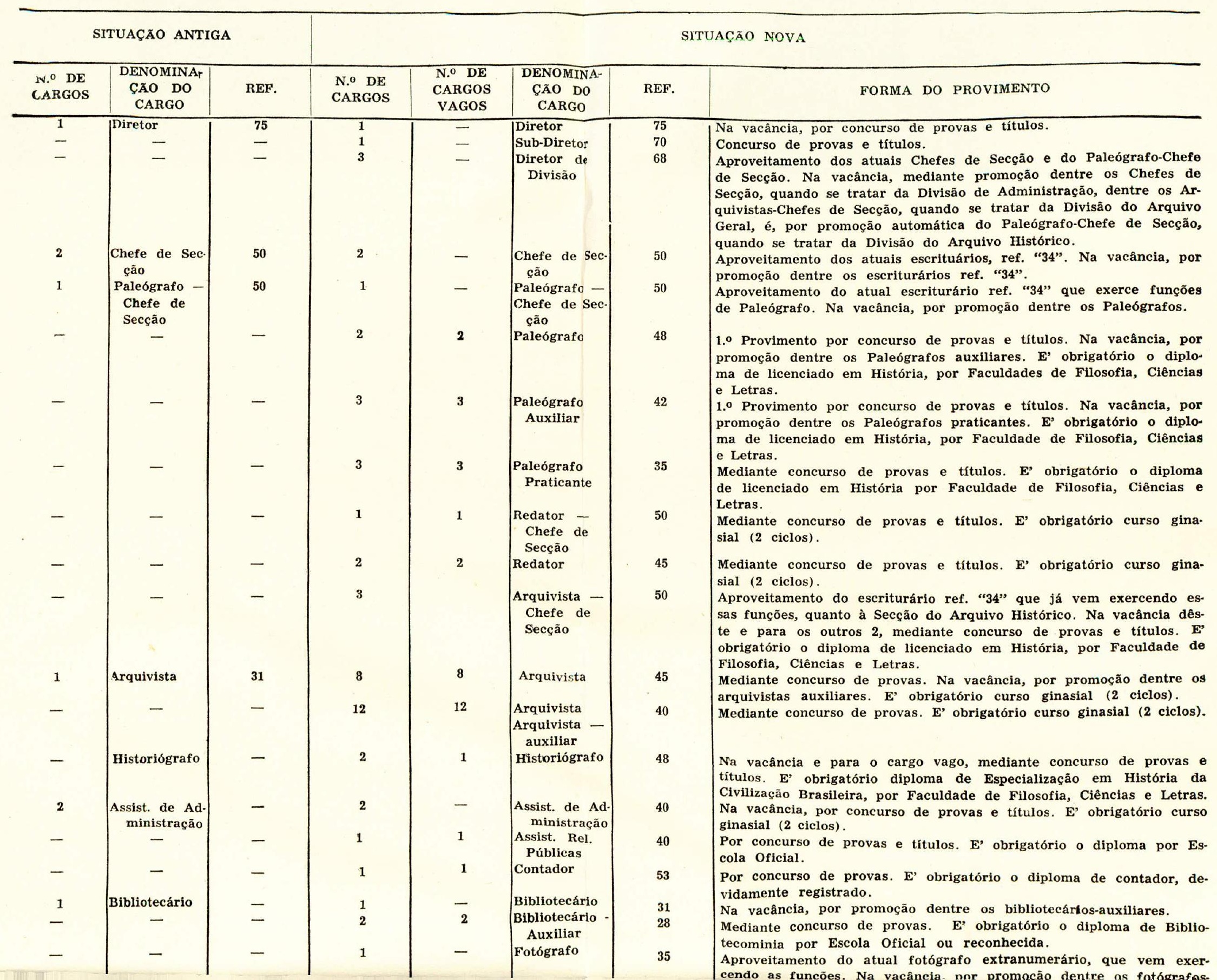




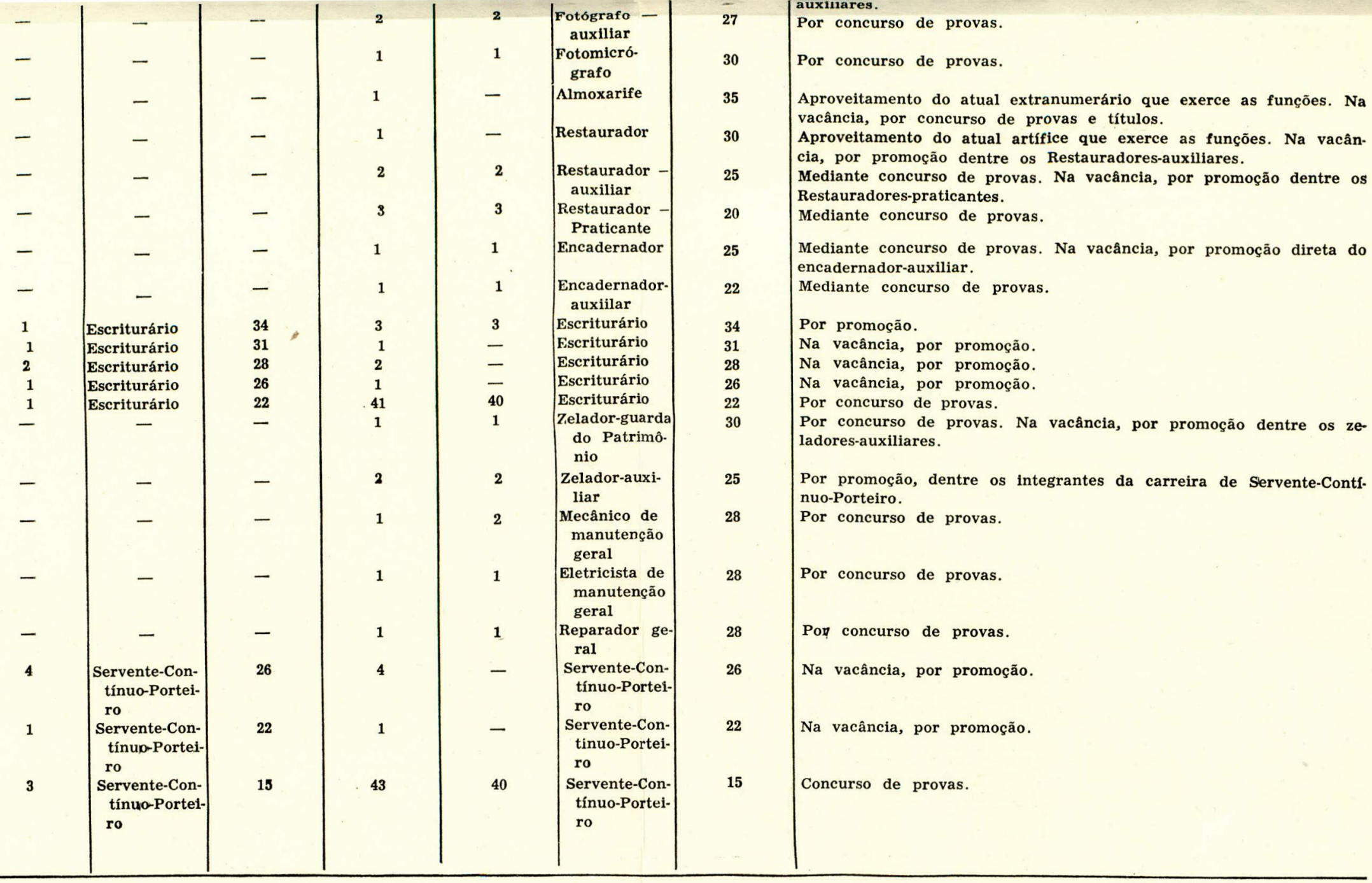




\section{CAP. III - Do Conselho do "Arquivo Geral do Estado"}

Artigo 13. ${ }^{\circ}$ - Fica criado o Conselho do Arquivo Geral do Estado, com as seguintes atribuições:

I - Orientar e opinar sôbre a matéria constante dos itens IV, $\mathrm{V}$ e VI, do artigo $2 .^{\circ}$, de que trata esta Lei.

II - Opinar sôbre a divulgação dos documentos históricos, quer pela seleção do material inédito a ser inserto nas publicações do Arquivo Geral do Estado, quer por meio de conferências, palestras, documentários cinematográficos, exposições, etc.

III - Orientar a aquisição de livros para a Biblioteca, e, sobretudo, a seleção dos documentos de que trata o artigo 16 desta Lei.

IV - Propor quaisquer outras medidas julgadas convenientes quer de ordem técnica, quer administrativa - à consecução dos objetivos do Arquivo Geral do Estado.

Artigo $14 .^{\circ}$ ) - O Conselho do Arquivo Geral do Estado será presidido pelo Secretário do Govêrno e composto pelos seguintes membros:

Diretor do Arquivo Geral do Estado.

Diretor da Divisão do Arquivo Histórico do Arquivo Geral do Estado.

1 Representante da Reitoria da Universidade de São Paulo.

1 Representante do Departamento de História da Faculdade de

Filosofia, Ciências e Letras da Universidade de São Paulo.

1 Representante do Instituto Histórico e Geográfico de São Paulo.

1 Representante da Sociedade de Estudos Históricos.

1 Representante do Centro de Estudos Históricos - dos alunos da Faculdade de Filosofia, Ciências e Letras de Marília.

1 Representante do Centro de Estudos Históricos - "Afonso d'E. Taunay" dos alunos da Faculdade de Filosofia, Ciências e Letras da Universidade de São Paulo.

1 Representante do Centro de Estudos Históricos da Faculdade de Filosofia, Ciências e Letras de Santos.

$\left.\S 10^{\circ}\right)$ - Os conselheiros serão nomeados pelo Secretário do Govêrno dentre listas triplices apresentadas pelas respectivas entidades.

\$2. ${ }^{\circ}$ ) - O Conselho reunir-se-á, com a presença da maioria dos seus membros uma vez em cada dois meses, e, extraordinàriamente, quando convocado por seu Presidente ou por 5 (cinco) de seus membros.

8 3. ${ }^{\circ}$ ) - O mandato dos conselheiros, à exceção dos dois primeiros, será de 3 anos, sendo permitida a recondução. 


\section{CAP. VI - Das Disposições Gerais.}

Artigo $15 .^{\circ}$ ) - Os documentos, processos, papéis ou livros serão transferidos, automàticamente, da Divisão do Arquivo Geral para a Divisão do Arquivo Histórico, ao completarem 50 (cinqüenta) anos dả data de sua origem.

Artigo 16. ${ }^{\circ}$ - Periòdicamente o Arquivo Geral do Estado procederá à seleção de documentos.

$\left.\S 1 .^{\circ}\right)$ - Os documentos considerados imprestáveis serão, obrigatòriamente, incinerados.

$\S 2 .^{\circ}$ - Nenhum documento será destruído antes de passados 5 (cinco) anos, da data de sua origem.

Artigo $\left.17 .^{\circ}\right)$ - Os documentos, processos, papéis ou livros, recolhidos à Divisão do Arquivo Histórico, só poderão sair do Arquivo Geral do Estado, mediante expressa autorização do Governador do Estado.

Artigo 18. ${ }^{\circ}$ - Nenhum documento do Arquivo Geral do Estado será divulgadó sem autorização do seu Diretor.

Artigo $19 .^{\circ}$ ) - Dentro de 60 dias, a partir da publicação da presente Lei, o Arquivo Geral do Estado modificará.o seu Regulamento, adaptando-o às novas disposições legais, e o Conselho do Arquivo Geral do Estado elaborará o seu Regimento Interno.

Artigo 22..$^{\circ}$ - Esta Lei entrará em vigor na data de sua publicação, sendo revogadas as disposiçöes em contrário (10).

10). - Ante-projeto de lei elaborado em 15 de junho de 1961 pelo Dr. José Soares de Souza, Diretor do Departamento do Arquivo do Estado (Nota da Redaçẫo). 